\title{
Renda Básica: A resposta está sendo soprada pelo vento
}

\author{
Basic Income: the answer is blowing in the wind
}

EDUARDO MATARAZZO SUPLICY*

RESUMO: Em palestra sobre o desenvolvimento da ideia de uma Renda Básica Incondicional proferida no dia 17 de agosto de 2002, na Universidade de São Paulo, o professor Phillipe Van Parijs afirmou que a introdução de um programa como esse, em países continentais como o Brasil, deve ser feita de forma gradual.

PALAVRAS-CHAVE: Renda básica; desigualdade; justiça social.

ABSTRACT: In a lecture on the development of the idea of an Unconditional Basic Income, issued on August 17, 2002, at the University of São Paulo, Professor Phillipe Van Parijs stated that the introduction of such a program in continental countries as Brazil should be made gradually.

KEYWORDS: Basic income; inequality; social justice.

JEL Classification: I38; P46.

Em palestra sobre o desenvolvimento da idéia de uma Renda Básica Incondicional proferida no dia 17 de agosto de 2002, na Universidade de São Paulo, o professor Phillipe Van Parijs afirmou que a introdução de um programa como esse, em países continentais como o Brasil, deve ser feita de forma gradual.

Logo após a palestra, em entrevista concedida à Folha de S.Paulo, Van Parijs respondeu a pergunta acerca da viabilidade da introdução do programa como sendo um direito à cidadania para todos os brasileiros. E tal programa pode ser implementado a partir de 2005 - ao final da primeira metade do mandato do próximo Presidente da República - conforme proposta contida em Projeto de Lei que apresentei no Senado Federal em dezembro de 2001.

\footnotetext{
* Professor de economia na Escola de Administração de Empresas da Fundação Getúlio Vargas - EAESP/ FGV, São Paulo/SP, Brasil. E-mail: emsuplicy@uol.com.br.
} 
Van Parijs ilustrou sua resposta com uma parábola. ${ }^{1}$ Recentemente, ele estava em um parque em Montevidéu, no Uruguai, e viu uma bonita escultura de bronze de um gaúcho em um carro de boi. O carro estava inclinado e atolado. Para sair do atoleiro fazia-se necessário muito esforço. Mas também se fazia necessário, para prevenir que atolasse novamente, que uma pessoa fosse à frente do carro, orientandoo no caminho a seguir. Essa pessoa é o "Eduardo".

Achei a história comovente e estimulante. De fato, muita coisa aconteceu no Brasil desde 1991, quando apresentei — e foi aprovado pelo Senado Federal - o Projeto de Lei que introduziria um programa de renda mínima na forma de um imposto de renda negativo. Na elaboração desse projeto tive a colaboração de Antonio Maria da Silveira, que em 1975 introduziu na literatura acadêmica brasileira a proposta de imposto de renda negativo.

No projeto está previsto que todos os homens ou mulheres com 25 anos ou mais, com renda mensal abaixo de $\mathrm{R} \$ 450,00$, terão o direito a um complemento de renda igual a $30 \%$ (ou até $50 \%$, dependendo da disponibilidade de recursos e da evolução do programa) da diferença entre este valor e sua renda pessoal. Em 16 de dezembro de 1991, após quatro horas de debates, o Senado brasileiro aprovou a proposição com voto favorável de todos os partidos. Apenas quatro senadores, num universo de 81, se abstiveram. Nesse dia, o líder do Partido da Social Democracia Brasileira (PSDB), hoje presidente da República, Fernando Henrique Cardoso, se referiu à proposta como uma utopia realista e com os pés no chão. O Senado contribuiu para torná-la realidade encaminhando-a à Câmara dos Deputados, onde, todavia, apesar do parecer favorável do seu relator, o deputado federal Germano Rigotto (PMDB/RS), permanece sem ser analisada há mais de dez anos. Se o projeto já estivesse em execução, o programa teria sido implementado gradualmente, partir de 1995 até 2002, tendo se iniciado pelas pessoas com 60 anos ou mais no primeiro ano, 55 anos ou mais no segundo ano e assim por diante. Hoje, todos os residentes do país, com 25 anos ou mais, já teriam acesso a esse direito, e estaríamos estudando a possibilidade de estendê-lo para as pessoas a partir dos 18 anos.

De fato, o Executivo federal exerce uma influência significativa na montagem da agenda das matérias a serem apreciadas pelo Congresso Nacional, mas nunca realizou nenhum movimento no sentido de levar essa proposição a votação. No entanto, a discussão em torno da introdução do Programa de Garantia de Renda Mínima, com o objetivo de erradicar a pobreza, estimulou a idéia da transferência de renda para famílias pobres com crianças em idade escolar, desde que estas esti-

\footnotetext{
${ }^{1}$ A entrevista do professor Phillipe Van Parijs concedida a Marcelo Billi foi totalmente gravada, mas, quando publicada pelo jornal Folha de S.Paulo, em 26 de agosto de 2002, p. B6, com o título Filósofo propõe renda mínima para todos, esta parábola foi omitida. A resposta de Van Parijs para a questão da factibilidade do meu projeto de lei para a implementação da renda básica em 2005 foi a seguinte: "Precisamos de uma pessoa que esteja à frente do seu tempo, que diga para as pessoas o quanto se pode avançar. Se você disser às pessoas que um projeto de renda básica para o Brasil só será um projeto realista em 2025, nada vai acontecer. Você precisa dizer que é para amanhã para que as coisas andem”.
} 
vessem efetivamente freqüentando a escola. Importantes para esse objetivo foram as contribuições de José Márcio Camargo, Cristovam Buarque, José Roberto Magalhães Teixeira e outros, que são relatadas detalhadamente em meu livro Renda de Cidadania: A Saída é pela Porta. ${ }^{2}$

Em 1995, tiveram início algumas experiências pioneiras de transferência de renda, primeiro na cidade de Campinas, Estado de São Paulo, onde o prefeito Magalhães Teixeira implantou o Programa de Garantia da Renda Familiar, e depois no Distrito Federal, onde o governador Cristovam Buarque introduziu o Programa Bolsa-Escola. Nos dois casos, as famílias com renda mensal inferior a 1/2 salário mínimo per capita tinham direito a receber um complemento de renda enquanto suas crianças em idade escolar estivessem freqüentando as aulas. Em Campinas, o benefício familiar foi definido como a quantia necessária para completar a metade de um salário mínimo vezes o número de membros da família; no Distrito Federal ele foi definido como um salário mínimo, independente do tamanho da família. De lá para cá, muitas administrações municipais, tais como Ribeirão Preto, São José dos Campos, Belém, Mundo Novo, Belo Horizonte, Piracicaba, Jundiaí, Blumenau e Caxias do Sul, dentre outras, instituíram programas semelhantes, que diferem entre si apenas na forma de calcular o benefício, mas são fundamentados no mesmo princípio.

Como resultado dessas experiências, entre 1995 e 1996 novos Projetos de Lei foram apresentados na Câmara dos Deputados e no Senado Federal, como o de Nelson Marchezan (PSDB), Ney Suassuna (PMDB) e Renan Calheiros (PMDB), que propuseram programas de renda mínima associados ou não à educação.

Em agosto de 1996, Phillipe Van Parijs esteve no Brasil a convite da Universidade de São Paulo (USP) e da Pontifícia Universidade Católica de São Paulo (PUCSP), ocasião em que o acompanhei em encontro com o presidente Fernando Henrique Cardoso. Nessa oportunidade, o professor Van Parijs afirmou que a implantação de programas de renda vinculados à educação era um passo positivo no caminho da introdução de uma garantia de renda mínima para todos. Existem boas razões para relacionar esses programas com investimento em capital humano. O deputado Nelson Marchesan, que também estava presente nesse encontro, usou o argumento de Van Parijs inúmeras vezes com o objetivo de estimular o Executivo Federal a coordenar, no Congresso Nacional, a aprovação da Lei Federal n ${ }^{\circ} 9.533$. Ela autorizou o governo federal a financiar $50 \%$ dos recursos destinados a programas municipais de garantia de renda mínima associados a atividades sócio-educativas. O benefício familiar foi definido de forma muito modesta e o programa foi introduzido gradualmente, expandindo-se das áreas pobres para as mais ricas.

Em abril de 2001, o presidente Fernando Henrique Cardoso sancionou a Lei $\mathrm{n}^{\circ} 10.219$, denominando-a de Lei José Roberto Magalhães Teixeira, em homenagem ao primeiro prefeito que implementou a idéia em Campinas, São Paulo, fale-

\footnotetext{
${ }^{2}$ SUPLICY, Eduardo Matarazzo (2002). Renda de Cidadania: A saída é pela porta. São Paulo: Cortez Editora/Fundação Perseu Abramo.
} 
cido em 1997. Essa lei autoriza o governo federal a estabelecer convênios com todas as administrações municipais brasileiras para adotar programas de renda mínima associados à educação ou programas de bolsa-escola. Segundo essa lei, os municípios são responsáveis pela administração do programa e o Executivo federal é o responsável pela provisão dos recursos monetários.

O programa está sendo implementado rapidamente no Brasil, especialmente quando consideramos as dimensões continentais do país. De acordo com Israel Luiz Stal, secretário-executivo desse programa executado pelo Ministério da Educação (MEC), em agosto de 2002, dos 5.561 municípios brasileiros, 5.536 já tinham firmado convênios com a União. Estão registradas no Programa Bolsa-Escola cerca de 5,1 milhões de famílias. O Orçamento Geral da União de 2002 alocou em torno de R 2 bilhões para cobrir os custos do programa. O secretário-executivo informa que, desse total, $\mathrm{R} \$ 1,6$ bilhão devem ser gastos com benefícios familiares, acrescidos de aproximadamente $\mathrm{R} \$ 100$ milhões com despesas administrativas. Após o início do programa, verificou-se, na maioria dos municípios, um incremento de cerca de $20 \%$ no número das famílias que preenchem os requisitos da lei e, portanto, são suas potenciais beneficiárias. O governo espera que ao final de 2002 o programa atinja 5,7 milhões de famílias.

A cada três meses, as administrações municipais informam à coordenação federal do programa a freqüência das 8,6 milhões de crianças registradas. Caso a criança não apresente uma freqüência de no mínimo $85 \%$ nas aulas ministradas, o recebimento do benefício é suspenso por três meses. Vale notar que, se em uma mesma família há duas crianças registradas e uma não atingiu a freqüência exigida, a interrupção do benefício é realizada apenas para um filho. No último trimestre, 60.000 crianças foram excluídas temporariamente do programa. Esse mecanismo tem contribuído significativamente para reduzir a evasão escolar.

Entrevistas com as famílias assistidas pelo programa indicam que essas pessoas estão felizes por terem, pela primeira vez na vida, um cartão magnético que pode ser usado no supermercado, por exemplo. Em junho de 2002, o governo federal anunciou a criação do Cartão do Cidadão e do Cadastro Único dos Programas Sociais. Eles serão formados, numa primeira etapa, por todos os programas de transferência de renda que existem nos vários organismos federais, tais como a BolsaEscola, a Bolsa-Alimentação, a Bolsa-Renda, o Programa de Erradicação de Trabalho Infantil - PETI, o Agente Jovem e o Auxílio-Gás. Na segunda etapa, os benefícios sociais estabelecidos pela Constituição de 1988 (a Previdência Rural, o Benefício de Prestação Continuada e a Renda Mensal Vitalícia $)^{3}$ também integrarão o Cartão e o Cadastro.

Enquanto o Ministério da Educação administra o Bolsa-Escola, o Ministério da Saúde administra o Bolsa-Alimentação. Este programa foi criado em 2001 com

\footnotetext{
${ }^{3}$ IPEA (Instituto de Pesquisa Econômica Aplicada); SEDH/MJ (Secretaria de Estado dos Direitos Humanos do Ministério da Justiça) e MRE (Ministério das Relações Exteriores) (2002). A Segurança Alimentar e Nutricional e o Direito Humano à Alimentação no Brasil. Brasilia, IPEA.
} 
o objetivo de transferir R \$ $15, \mathrm{R} \$ 30$ ou no máximo $\mathrm{R} \$ 45$ por mês para famílias com renda mensal menor que 1/2 salário mínimo e com 1,2 ou mais crianças com até seis anos de idade ou mães grávidas com problemas nutricionais. Em agosto de 2002, o programa envolvia 675 mil famílias, beneficiando 3,5 milhões de pessoas, incluindo 2,7 milhões de crianças e 800 mil grávidas, abrangendo 3.032 municípios ou $80 \%$ das administrações municipais. O dispêndio total do programa atinge o montante de R $\$ 300$ milhões.

O Programa de Erradicação do Trabalho Infantil - PETI, do Ministério da Previdência e Assistência Social, transfere mensalmente R \$ 25,00 na zona rural e $\mathrm{R} \$ 40,00$ nas áreas urbanas para as famílias que moram em regiões com grave incidência de trabalho infantil penoso. Das famílias beneficiadas exige-se que retirem suas crianças de 7 a 14 anos dessas atividades e as enviem para a escola, que funciona em jornada ampliada. Neste ano de 2002, o programa registra $720 \mathrm{mil}$ crianças com um dispêndio em torno de $\mathrm{R} \$ 235,8$ milhões.

O Programa Jovem Agente, do Ministério da Previdência e Assistência Social, transfere mensalmente $\mathrm{R} \$$ 65,00 para jovens de 15 a 17 anos de famílias em situação de risco, que, em contrapartida, devem freqüentar a escola e engajar-se em trabalhos comunitários. Aproximadamente 40.000 jovens são atendidos por esse programa e seu dispêndio será de R \$ 51,9 milhões em 2002.

O Programa Bolsa-Renda, administrado pelo Ministério da Integração Nacional, transfere mensalmente $\mathrm{R} \$ 60,00$ para famílias pobres que vivem em situações emergenciais e requer que as crianças dos beneficiários em idade escolar estejam freqüentando a escola. Famílias com 4 ou mais membros recebem R 120,00 por mês. Os benefícios totalizarão R $\$ 253,3$ milhões e abrangerão 900 mil agricultores em 2002.

O Programa Auxílio-Gás, administrado pelo Ministério das Minas e Energia, transfere mensalmente $\mathrm{R} \$ 15,00$ para famílias pobres, incluindo aquelas beneficiadas por outros programas. 5,7 milhões de pessoas estão nesse programa e o dispêndio contabilizado, em 2002, atinge $\mathrm{R} \$ 900$ milhões.

O Ministério da Previdência e Assistência Social também administra o Benefício de Assistência Continuada (BAC), que transfere mensalmente recursos da ordem de um salário mínimo para pessoas idosas ou pessoas que necessitam de cuidados especiais ou com deficiência física e para as famílias com renda abaixo de 1/4 do salário mínimo per capita que não recebam outro benefício do mesmo Ministério ou o Seguro-Desemprego. O programa abrange 1,3 milhão de inválidos ou de pessoas que necessitam de cuidados especiais e cerca de 740.000 idosos protegidos pelo Seguro Social. O total gasto com esses programas é, em 2002, de cerca de R\$ 3,7 bilhões.

Finalmente, o Ministério da Previdência e Assistência Social transfere, mensalmente e de forma permanente, um salário mínimo para pessoas idosas, viúvas, em recuperação de acidentes de trabalho ou doentes que tenham trabalhado em atividades rurais em regime de economia familiar, na condição de portadores de "Segurados Especiais" da Previdência Social. Há 7,3 milhões de aposentados e pensionistas e o total de recursos previstos para 2002 contabilizam R \$ 15,3 bilhões. 
Totalizando os dispêndios de todos os programas citados, chegamos ao valor de R \$22,4 bilhões em 2002. No entanto, como poderemos evitar que o já citado Cartão do Cidadão seja o símbolo da não-cidadania e da exclusão, como vaticinou Antonio Delfim Netto no jornal Folha de S.Paulo? ${ }^{4}$ Hoje, após refletir muito sobre qual a melhor forma de garantir uma renda para todos, após interagir com todos os membros da BIEN, ${ }^{5}$ após ler os trabalhos de Phillipe Van Parijs, Guy Standing,

Clauss Offe, Tony Atkinson, James Tobin, James Edward Meade, entre outros, estou convencido de que a melhor resposta a essa indagação será a implementação de uma renda incondicional ou de uma renda cidadã que atinja a todos eqüitativamente e independentemente da origem da pessoa, da raça, idade, estado civil ou condição socioeconômica. ${ }^{6}$

É importante registrar que hoje no Brasil existem várias administrações municipais que executam programas de garantia de renda mínima relacionados às oportunidades educacionais, com benefícios mais generosos do que os definidos pela lei federal, o que é perfeitamente possível. O município pode usar os recursos federais para o programa definido pela lei federal e complementá-lo segundo os critérios municipais. Isso também pode ocorrer nos Estados onde o governador e a Assembléia

\footnotetext{
${ }^{4}$ Em 29 de maio de 2002.

${ }^{5}$ A minha primeira participação nesse fórum foi no V Congresso Internacional realizado em Londres, em 1994; também estive presente no VI Congresso ocorrido em Viena, 1996; não pude comparecer ao VII Congresso em Amsterdã porque estava em campanha eleitoral para o Senado Federal, mas voltei a participar no VIII Congresso em Berlim.
}

${ }^{6}$ VAN PARIJS, Philippe (2001). What's Wrong with a Free Lunch? Foreword by Robert M. Solow. New Democracy Forum Series. Boston, Beacon Press; (1995). Real Freedom for All: What (if anything) Can Justify Capitalism? Oxford, Oxford University Press; (1994). "Au delà de la solidarité. Los fondements éthiques de l'Etat-providence et de son dépaassement". Futuribles, Revista Mensal, $\mathrm{n}^{\circ}$ 184, fevereiro, pp. 5-29; (ed.) (1992). Arguing for Basic Income: Ethical Foundations for a Radical Reform. London, Verso; (1991). Qu'est-ce qu'une Société Juste? Introduction à la Pratique de la Philosophie Politique, Paris, Le Seuil ("La Couleur des idées").

STANDING, Guy (1999). Global Labour Flexibility: Seeking Distributive Justice. New York, Ed. St. Martins Press.

OFFE, Claus (1998). “O novo poder”. Veja, São Paulo, 04 de abril; (1992); “A Non-Productivistic Design for Social Policies”. In.: VAN PARIJS, Philippe (ed.) (1992). Arguing for Basic Income: Ethical Foundations for a Radical Reform. London, Verso.

ATKINSON, Anthony.B. (1998) Poverty in Europe. New York, Blackwell Publishers; (1995) Public Economics in Action: The Basic Income/Flat Tax Proposal. The Lindahl lectures. New York, Oxford University Press.

TOBIN, James (1965). “On the Economic Status of the Negro”. Daedalus 94(4), Fall 1965, 878-98; (1970). "Raising the Incomes of the Poor". In: GORDON, K. (ed.) (1970). Agenda for the Nation. Washington, DC, Brookings Institution.; (1987). Policies for Prosperity: Essays in a Keynesian Mode. Cambridge, MA, The MIT Press.

MEADE, James Edward (1935). "Outline of economic policy for a labour govemment”. In: HOWSON, S. (ed.) (1988). The Collected Papers of James Meade. Volume I, Employment and Inflation. London, Unwin Hyman; (1989). Agathotopia: The Economics of Partnership. Aberdeen, Aberdeen University Press; (1993). Liberty, Equality and Efficiency. Apologia pro Agathotopia Mea. London, Macmillan Press; (1995). Full employment regained? An agathotopian dream. Cambridge, Cambridge University Press. 
Legislativa desejem definir um novo desenho do programa para todas as municipalidades. Inúmeras cidades, principalmente as administradas pelo Partido dos Trabalhadores, têm programas melhores, como a cidade de São Paulo, hoje administrada pela prefeita Marta Suplicy. Em outubro de 2000, em Berlim, ${ }^{7}$ no VIII Congresso Internacional da BIEN, afirmei que Marta estava próxima da vitória no pleito eleitoral para a Prefeitura de São Paulo — pois naquele momento liderava as pesquisas eleitorais - e que deveria iniciar a implantação do Programa de Garantia de Renda Mínima caso fosse eleita. Após sua posse em 2001, ela efetivamente o fez.

Hoje, a cidade de São Paulo, a maior do Brasil, tem cerca de 14 milhões de habitantes, sendo que, desse total, 178.590 famílias estão assistidas pelo Programa de Renda Mínima. Famílias com renda mensal inferior a 1/2 salário mínimo per capita e com filhos entre 6 e 15 anos freqüentando a escola têm o direito de receber um complemento de renda de valor igual a $2 / 3$ da subtração entre as parcelas correspondentes ao número de membros da família vezes a metade do salário mínimo, e a renda familiar. O programa está sendo ampliado para atender a cerca de 300.000 famílias. A prefeitura contemplou primeiro as famílias pobres, nas quais se verificava as maiores taxas de desemprego e de violência criminal e as menores rendas per capita. Após um ano e meio de vigência, os resultados positivos são evidentes nas localidades onde o programa foi implementado. É grande a presença das crianças na escola, observou-se um incremento na atividade econômica dessas áreas, com conseqüente redução da criminalidade.

Algumas abordagens detalhadas e abrangentes dos efeitos desses programas estão sendo preparadas. Maria Ozanira Silva e Silva e Lena Lavinas, que pesquisam há muitos anos as experiências de renda mínima, também apresentaram trabalhos no IX Congresso Internacional da BIEN, com importantes contribuições ao tema. Ademais, Maria Ozanira, com outros pesquisadores, está organizando um seminário de avaliação de todas as experiências de renda mínima no Brasil, que ocorrerá em novembro de 2002, em Campinas, São Paulo.

No Brasil, teremos um pleito eleitoral muito importante, nos dias 6 e 27 de outubro - caso o segundo turno torne-se necessário - para presidente da República, governadores, senadores, deputados federais e estaduais. Até agora, Luiz Inácio Lula da Silva, candidato do Partido dos Trabalhadores à presidência da República, lidera todas as pesquisas eleitorais. Em seu plano de governo, há um capítulo denominado Inclusão Social, que dá destaque para as Políticas de Garantia de Renda Mínima como um dos meios para a erradicação da fome. Está registrado que o governo da coalizão liderada pelo PT irá implementar os seguintes itens programáticos: a complementação da renda das famílias pobres com filhos até 15 anos em todos os programas municipais; a adoção de bolsas de estudos para jovens entre 15 e 25 anos oriundos de famílias pobres, permitindo que essas pessoas completem seus estudos intermediários e superiores; a garantia de uma renda mínima

\footnotetext{
${ }^{7}$ Cidade sede do VIII International Congress of the Basic Income European Network - BIEN. Neste encontro apresentei o texto Em Direção a uma Renda de Cidadania.
} 
para todos os trabalhadores desempregados entre 22 e 50 anos de idade, de modo que possam exercer uma atividade profissional qualificada na comunidade - isso será feito por meio do pagamento do seguro-desemprego para os trabalhadores do mercado formal e por meio de um benefício para aqueles do mercado informal - e finalmente o Programa Nova Oportunidade, destinado aos desempregados entre 51 e 66 anos de idade. Nesse mesmo capítulo está registrado que o Programa de Erradicação da Fome será implementado imediatamente, com a distribuição do "cartão-alimentação" para todas as famílias pobres para que possam comprar os alimentos de que necessitam.

É importante também ressaltar que o plano de governo de Lula afirma que a renda mínima na sua proposta de governo deve ser vista como uma etapa para a implementação — quando a restrição fiscal permitir — da Renda Básica de Cidadania.

Nos comícios recentes de sua campanha presidencial, Lula afirma que a questão que mais preocupa os brasileiros é a relacionada ao emprego, e o que dá mais orgulho a um homem ou a uma mulher é trabalhar e receber os recursos necessários para sua sobrevivência com dignidade. No Brasil de nossos sonhos, segundo Lula, nenhum prefeito terá que distribuir cestas básicas ou uma renda mínima para as famílias mais pobres. Por conseguinte, todos deverão ter o direito a um emprego com um salário decente, sendo que as políticas econômicas devem ter esse objetivo como alvo.

Devemos ver a concessão de uma renda mínima como uma humilhação para as pessoas? De forma nenhuma, especialmente se compreendermos este problema como Thomas Paine, em Agrarian Justice (1796), em que afirma que a renda mínima não deveria ser vista como uma caridade, mas sim como um direito. ${ }^{8}$ Todas as pessoas devem ter o direito de participar da riqueza da nação e da terra. Conseqüentemente, renovo a minha proposta para que renomeemos a Bien para Basic Income Earth Network.

Igualmente importante é entender, principalmente para os países em desenvolvimento da América Latina, África ou Ásia, que a introdução dos Programas de Renda Básica ou Renda de Cidadania é compatível com o incremento da competividade das economias nacionais.

Os países desenvolvidos criaram vários desenhos de Crédito Fiscal por Remuneração Recebida, ${ }^{9}$ de salário-família e de programas de garantia de renda mínima.

\footnotetext{
${ }^{8}$ PAINE, Thomas (1796). Agrarian Justice. In: FONER, P.F. (ed.) (1974). The Life and Major Writings of Thomas Paine. Secaucus, NJ, Citatel Press.

${ }^{9}$ Este é um programa cuja forma de calcular o benefício está baseada na situação financeira dos beneficiários. O seu valor varia inversamente aos valores dos rendimentos dos indivíduos ou das famílias. Por exemplo, à medida que a renda do beneficiário aumenta, o valor do benefício reduz-se; e, quando ocorre a redução desses rendimentos, o valor do benefício sofre um incremento. A Renda Mínima de Inserção (Revenu Minimum D’Insertion - RMI), na França, e o Crédito Fiscal por Remuneração Recebida (Earned Income Tax Credit - EITC), nos Estados Unidos, são exemplos desse programa. A RMI garante que toda pessoa de 25 anos ou mais, cuja renda não atinja 2.600 francos, tem o direito a um complemento de renda. O EITC confere a todo trabalhador que tenha uma família e uma renda inferior a determinado patamar (de US\$ 30 mil dólares anuais, no caso de duas ou mais crianças) o
} 
Isso significa que em cada país a sociedade decidiu incrementar os impostos (tributos, taxas etc.) o suficiente para aumentar os salários dos trabalhadores de modo que sua renda total fosse superior ao nível de pobreza estabelecido nesses países. Tais instrumentos ampliam o grau de liberdade dos trabalhadores, melhorando seu poder de barganha - pois assim não necessitam aceitar qualquer atividade econômica para sobreviver. Ao mesmo tempo, as empresas estão cientes de que os trabalhadores têm um complemento de renda na forma de crédito fiscal ou de renda mínima. Sendo assim, a renda mínima estaria ampliando o grau de exploração dos trabalhadores? $\mathrm{Na}$ realidade, do ponto de vista dos trabalhadores é muito melhor existir esse programa de renda mínima, que lhes dá um maior poder de barganha, mas mais do que isso. Se é verdade que as empresas ampliaram a oferta de empregos em função da existência da renda mínima ou dos programas de crédito fiscal, logo qual será o efeito final sobre o mercado de trabalho? A resposta é um incremento da oferta de empregos pelas empresas e o aumento dos salários, como está claramente demonstrado por Samuel Britain em Capitalism with a Human Face (1995). ${ }^{10}$

Este tema ainda não está presente no debate brasileiro, nem entre as autoridades federais, estaduais ou municipais. Apenas alguns poucos, como Márcio Pochmann, secretário de Desenvolvimento, Trabalho e Solidariedade do Município de São Paulo, e Ana Fonseca, coordenadora do Programa de Renda Mínima do Município de São Paulo, começaram a discutir essa questão seriamente. Eles têm analisado os efeitos dos programas sociais (Renda Mínima, Bolsa-Trabalho, Começar de Novo, Programa Solidariedade, São Paulo Confia) implantados na cidade e a melhor forma de aperfeiçoá-los. ${ }^{11}$

Uma vez que compreendamos que todos os brasileiros têm o direito a uma renda básica incondicional, da mesma forma que todo cidadão possui o direito de visitar o Parque Ibirapuera, na cidade de São Paulo, ou de nadar nas águas da praia de Copacabana, no Rio de Janeiro, vamos também compreender que a Renda Básica significará a ampliação da liberdade e da dignidade no sentido descrito por Amartya Sen em Desenvolvimento como Liberdade (1999), em que ele diz que, para um país ser realmente desenvolvido, deve proporcionar um maior grau de liberdade para todos os seus habitantes. ${ }^{12}$

Durante os anos 90, quando tomei conhecimento da idéia de uma renda básica para todos, minha primeira reação foi de querer garantir esse direito para os pobres na forma de um imposto de renda negativo, como está proposto no Projeto

direito de receber uma quantia em dinheiro que lhe permita alcançar uma renda maior e, assim, superar a sua condição de pobreza.

${ }^{10}$ BRITTAIN, Samuel (1995). Capitalism with a Human Face. Aldershot, Edward Elgar.

${ }^{11}$ POCHMANN, Marcio (org.) (2002). Desenvolvimento, Trabalho e Solidariedade: Novos Caminhos para a Inclusão Social. São Paulo: Cortez Editora e PREFEITURA MUNICIPAL DE SÃO PAULO/ SECRETARIA DO DESENVOLVIMENTO, TRABALHO E SOLIDARIEDADE (2002). Programas Sociais da Prefeitura de São Paulo: Avaliação Preliminar. São Paulo, mimeo.

12 SEN, Amartya (1999).Desenvolvimento como Liberdade. São Paulo, Companhia das Letras, 2000. 
de Lei que apresentei em 1991. Entretanto, atualmente estou completamente convencido de que com os modernos sistemas computacionais será mais simples e racional estender a todos o mesmo direito de receber uma modesta renda. $\mathrm{O}$ rico também terá direito a essa renda, entretanto irá contribuir mais do que receber. A burocracia será minimizada. Qualquer tentativa de estigmatização dos beneficiários do programa será eliminada. As pessoas saberão, previamente, que uma modesta e crescente renda será destinada a cada membro da família e será paga nos próximos 12 meses e nos anos seguintes.

Um exemplo dessa idéia foi introduzido em 1976 pelo governador Jay Hammond, do Estado norte-americano do Alasca, quando propôs à Assembléia Legislativa que destinasse $50 \%$ dos royalties originários dos recursos naturais, principalmente os do petróleo, para um fundo de propriedade de todos os residentes no Estado. A idéia foi aprovada por um referundum popular. Decidiu-se também que os recursos do Fundo Permanente do Alasca seriam aplicados no mercado financeiro, em ações de empresas do Alasca e de outras companhias norte-americanas no exterior, e em ativos reais. Desde então, cada morador do Estado registrado no Fundo recebe todo ano, no mês de outubro, dividendos que, em 2001, foram de aproximadamente US $\$ 1,850.00 .{ }^{13}$

Nos últimos anos, em minhas palestras sobre a renda de cidadania, sempre explico que este debate já estava presente na obra de Bertrand Russell Os Caminhos para a Liberdade (1918). ${ }^{14}$ Seria esse benefício um incentivo à inatividade? $\mathrm{O}$ que faremos com as pessoas que têm uma tendência inevitável para o ócio? Digo que não devemos pensar muito sobre essas pessoas, pois elas são poucas. Há muitas atividades importantes, como cuidar de crianças e idosos, que nem sempre são remuneradas. Há também inúmeros trabalhos relevantes para a humanidade que não são reconhecidos pelo mercado, mas mesmo assim continuam sendo produzidas e são muito relevantes, como os trabalhos de Franco Modigliani e Vincent Van Gogh. A Constituição Brasileira, assim como a da maioria das nações, reconhece o direito à propriedade privada. Isso implica que reconheçamos como legítimo que os proprietários do capital recebam aluguéis, juros e lucros. A Carta Magna, no entanto, não obriga que essas pessoas trabalhem. Mas em geral elas trabalham, bem como suas crianças vão à escola. Por quê? Porque é da natureza humana a busca da prosperidade e do progresso. Bem, se permitimos que os ricos recebam uma renda sem trabalhar, porque não devemos permitir que todos, ricos e pobres, recebam uma renda, mesmo que modesta? É uma pergunta muito simples. Tão simples como o fato de que as pessoas saem de casa pela porta, como foi dito por Confúcio no Livro das Explicações e Respostas, resga-

\footnotetext{
${ }^{13}$ Um total de aproximadamente R \$ 5.550,00, com a taxa de câmbio de R \$/US\$ 3,00.

${ }^{14}$ RUSSELL, Bertrand (1918) Os Caminhos para a Liberdade: Socialismo, Anarquismo e Sindicalismo. Rio de Janeiro, Zahar, 1977.
} 
tado por Guy Standing. ${ }^{15}$ Por isso é que o subtítulo do meu livro Renda de Cidadania é A Saída é pela Porta.

Tenho certeza de que, se tivéssemos introduzido a Renda de Cidadania no Brasil, não teríamos razão para que o poeta popular Patativa do Assaré escrevesse a maravilhosa canção Triste Partida, que foi gravada em 1966 pelo cantor nordestino Luiz Gonzaga:

TRISTE PARTIDA

Patativa do Assaré

"Eu vendo meu burro

Meu jegue e o cavalo

Nós vamos a São Paulo

Viver ou morrer

[...]

Pois logo aparece

Feliz fazendeiro

Por pouco dinheiro

Lhe compra o que tem

[...]

Meu Deus, meu Deus

Faz pena o nortista

Tão forte, tão bravo

Viver como escravo No Norte e no Sul”

Se no Brasil a renda básica já fosse uma realidade, os jovens das periferias de todas as cidades do Brasil não necessitariam estar cantando o rap Homem na Estrada, dos Racionais MC's, composta por Mano Brown. A canção, que significa muito para os jovens, diz:

\section{HOMEM NA ESTRADA}

Mano Brown, dos Racionais MCs

"Um homem na estrada recomeça sua vida.

Sua finalidade: a sua liberdade.

Que foi perdida, subtraída;

e quer provar a si mesmo que realmente mudou, que se recuperou e quer viver em paz.

Não olhar para trás, dizer ao crime: nunca mais!

Pois sua infância não foi um mar de rosas, não.

$\mathrm{Na}$ Febem, lembranças dolorosas, então.

Sim, ganhar dinheiro, ficar rico, enfim.

\footnotetext{
${ }^{15}$ CONFÚCIO. O livro das explicações e respostas em 20 capítulos (2001). São Paulo: Landy Livraria e Editora.
} 
Muitos morreram, sim, sonhando alto assim, me digam quem é feliz, quem não se desespera, vendo nascer seu filho no berço da miséria! Um lugar onde só tinham, como atração, o bar, e o candomblé pra se tomar a bênção.

Esse é o palco da história que por mim será contada.

O homem na estrada.

Equilibrado num barraco incômodo, mal acabado e sujo, porém, seu único lar, seu bem e seu refúgio.

Um cheiro horrível de esgoto no quintal, por cima ou por baixo, se chover será fatal. Um pedaço do inferno, aqui é onde eu estou. Até o IBGE passou aqui e nunca mais voltou.

Numerou os barracos, fez uma pá de perguntas.

Logo depois esqueceram, filhos da puta!

Acharam uma mina morta e estuprada, deviam estar com muita raiva.

'Mano, quanta paulada!'

Estava irreconhecível. O rosto desfigurado.

Deu meia-noite e o corpo ainda estava lá.

Coberto com lençol, ressecado pelo sol, jogado...

O IML estava só dez horas atrasado!

Sim, ganhar dinheiro, ficar rico, enfim!

Quero que meu filho nem se lembre daqui,

tenha uma vida segura.

Não quero que ele cresça com um "oitão" na cintura

e uma "PT" na cabeça.

E o resto da madrugada sem dormir, ele pensa

o que fazer para sair dessa situação?

Desempregado, então.

Com má reputação.

Viveu na detenção.

Ninguém confia não.

... e a vida desse homem para sempre foi danificada.

O homem na estrada...

O homem na estrada...

Amanhece mais um dia e tudo é exatamente igual.

Calor insuportável, 28 graus.

Faltou água, já é rotina, monotonia.

Não tem prazo pra voltar, hã! já fazem cinco dias!

São dez horas, a rua está agitada, uma ambulância foi chamada com extrema urgência.

Loucura, violência exagerada!

Estourou a própria mãe, estava embriagado. 
Mas bem antes da ressaca ele foi julgado.

Arrastado pela rua o pobre do elemento, o inevitável linchamento, imaginem só!

Ele ficou bem feio, não tiveram dó.

Os ricos fazem campanha contra as drogas

e falam sobre o poder destrutivo delas.

Por outro lado, promovem e ganham muito dinheiro

com o álcool que é vendido na favela.

Empapuçado ele sai, vai dar um rolê.

Não acredita no que vê, não daquela maneira,

crianças, gatos, cachorros disputam palmo a palmo

seu café da manhã na lateral da feira!

Molecada sem futuro, eu já consigo ver:

só vão na escola pra comer, apenas, nada mais!

Como é que vão aprender?

Sem incentivo de alguém, sem orgulho e sem respeito,

sem saúde e sem paz.

Um mano meu tava ganhando um dinheiro,

tinha comprado um carro,

até rolex tinha!

Foi fuzilado à queima-roupa no colégio,

abastecendo a playboyzada de farinha!

Ficou famoso, virou notícia, endeu dinheiro aos jornais, hu!, cartaz à polícia

Vinte anos de idade, alcançou os primeiros lugares...

superstar do Notícias Populares!

Uma semana depois chegou o crack, gente rica por trás, diretoria!

Aqui, periferia, a miséria é de sobra.

Um salário por dia garante a mão-de-obra.

A clientela tem grana e compra bem, tudo em casa, costa quente de sócio.

A playboyzada muito louca até os ossos!

Vender droga por aqui, grande negócio!

Sim, ganhar dinheiro, ficar rico, enfim,

Quero um futuro melhor, não quero morrer assim,

num necrotério qualquer, como indigente,

sem nome e sem nada...

O homem na estrada.

Assaltos na redondeza levantaram suspeitas.

Logo acusaram a favela para variar,

E o boato que corre é que esse homem está, com o seu nome lá na lista dos suspeitos, pregada na parede do bar. 
A noite chega e o clima estranho no ar, e ele sem desconfiar de nada, vai dormir tranqüilamente, mas na calada cagüetaram seus antecedentes, omo se fosse uma doença incurável, no seu braço a tatuagem, DVC, uma passagem, 157 na lei... No seu lado não tem mais ninguém. A Justiça Criminal é implacável. Tiram sua liberdade, família e moral. Mesmo longe do sistema carcerário, te chamarão para sempre de ex-presidiário! Não confio na Polícia, raça do caralho! Se eles me acham baleado na calçada, chutam minha cara e cospem em mim! É... Eu sangraria até a morte... Já era, um abraço!

Por isso a minha segurança eu mesmo faço. É madrugada, parece estar tudo normal.

Mas esse homem desperta, pressentindo o mal, muito cachorro latindo.

Ele acorda ouvindo barulho de carro e passos no quintal.

A vizinhança está calada e insegura, premeditando o final que já conhece bem.

$\mathrm{Na}$ madrugada da favela não existem leis, talvez a lei do silêncio, a lei do cão talvez.

Vão invadir o seu barraco, é a polícia!

Vieram pra arregaçar, cheios de ódio e malícia!

Filhos da puta, comedores de carniça!

Já deram minha sentença e eu nem tava na "treta"!

Não são poucos e já vieram muito loucos!

Matar na crocodilagem, não vão perder viagem.

Quinze caras lá fora, diversos calibres, e eu apenas com uma "treze tiros" automática.

Sou eu mesmo e eu, meu Deus e o meu orixá.

No primeiro barulho, eu vou atirar.

Se eles me pegam, meu filho fica sem ninguém!

E o que eles querem: mais um "pretinho" na Febem!

Sim, ganhar dinheiro, ficar rico enfim,

a gente sonha a vida inteira e só acorda no fim, minha verdade foi outra, não dá mais tempo pra nada...” (tiros)

(Trecho radiofônico: 'Homem mulato aparentando entre 25 e 30 anos é encontrado morto na estrada do M'Boi Mirim sem número. Tudo indica ter sido acerto de contas entre quadrilhas rivais. Segundo a Polícia, a vítima tinha vasta ficha criminal...'). 
Tenho certeza de que a instituição de uma Renda Básica Incondicional é um instrumento de política econômica que está entre os mecanismos que são consistentes com o objetivo de construir uma sociedade justa e organizada, como recomendado por Paul e Greg Davidson em Economics for a Civilized Society (1988). ${ }^{16}$ Outros instrumentos são a reforma agrária, o estimulo às cooperativas, a expansão das instituições de microcrédito, a expansão da educação, saúde e assistência social etc. A implementação desses mecanismos leva em consideração os valores que foram sintetizados por Martin Luther King Jr. em 1963:17

Eu tenho um sonho de que um dia todo o vale será elevado, todo morro e toda montanha serão rebaixados, os lugares acidentados serão tornados planos, os lugares tortuosos serão tornados retos e a glória do Senhor será revelada e todos, juntos, verão isso acontecer.

Esse será o dia em que todas as crianças de Deus serão capazes de cantar com um novo sentido - "Meu país é de você; doce terra da liberdade; de você eu canto; terra onde meus pais morreram, terra do orgulho dos peregrinos; de todos os lados das montanhas, deixai a liberdade soar"- e se for para a América se tornar uma grande nação, isso precisa se tornar uma verdade.

E quando nós deixarmos a liberdade soar, quando nós a deixarmos soar em todas as vilas e vilarejos, em todas as cidades e Estados, nós poderemos ver mais depressa a chegada do dia em que todas as crianças de Deus - homens negros e homens brancos, judeus e gentis, católicos e protestantes - serão capazes de se darem as mãos e cantarem as palavras daquele velho hino espiritual negro: "Finalmente a liberdade; finalmente a liberdade; graças a Deus todo-poderoso, nós somos finalmente livres".

Certamente a Renda Básica é um dos principais instrumentos de política econômica que deveria estar no centro das negociações dos principais conflitos sociais que estão ocorrendo em várias nações do mundo. A Renda de Cidadania poderia ser também um tópico importante nas discussões de integração das áreas econômicas. A Renda Básica é uma solução tão óbvia quanto o fato de sabermos que a melhor saída é pela porta. Nós podemos também dizer, como Bob Dylan o fez na canção, que a resposta está pairando ao vento (Blowin' in the Wind):

\section{BLOWIN' IN THE WIND}

Bob Dylan

How many roads must a man walk down

Before you call him a man?

Yes, 'n' how many seas must a white dove sail

Before she sleeps in the sand?

Yes, 'n' how many times must the cannon balls fly

\footnotetext{
${ }^{16}$ DAVIDSON, Greg e DAVIDSON, Paul (1988). Economics for a Civilized Society. London: Macmillan.

${ }^{17}$ KING Jr., Martin Luther (1997). Where do We Go from Here: Chaos or Community? New York, Harper Row, 1967.
} 
Before they're forever banned?

The answer, my friend, is blowin' in the wind,

The answer is blowin' in the wind.

How many years can a mountain exist

Before it's washed to the sea?

Yes, 'n' how many years can some people exist

Before they're allowed to be free?

Yes, 'n' how many times can a man turn his head,

Pretending he just doesn't see?

The answer, my friend, is blowin' in the wind,

The answer is blowin' in the wind.

How many times must a man look up

Before he can see the sky?

Yes, 'n' how many ears must one man have

Before he can hear people cry?

Yes, 'n' how many deaths will it take till he knows

That too many people have died?

The answer, my friend, is blowin' in the wind,

The answer is blowin' in the wind.

É muito importante que, em países como o Brasil e a África do Sul, esteja crescendo o interesse pelo uso da Renda Básica, com a compreensão de que ela é compatível com a sustentabilidade do desenvolvimento econômico. De acordo com o último Relatório de Desenvolvimento Humano das Nações Unidas, de 2002, o Brasil e a África do Sul estão classificados em $4^{\circ}$ e $6^{\circ}$ lugares entre os países de maior desigualdade social, com um Índice de Gini, respectivamente, de 60,7 (1998) e 59,3 (1993-1994), e com uma renda per capita de US\$ 7,625.00 e US\$ 9,401.00. Segundo o Índice de Desenvolvimento Humano, da mesma instituição, essas nações estão classificadas nas posições de $73^{\circ}$ e $107^{\circ}$. A implementação de um Programa de Renda Básica nessas nações pode constituir-se em uma etapa significativa para atingir os objetivos de erradicação da pobreza e de diminuição da desigualdade social, permitindo que as pessoas possam viver com maior dignidade e liberdade. 